\title{
Common Markets, Economic Growth, and Creative Destruction
}

\author{
Tapio Palokangas* \\ Department of Economics, University of Helsinki \\ Discussion Paper No. 594:2004 \\ ISBN 952-10-1524-1, ISSN 1459-3696
}

March 11, 2004

\begin{abstract}
Economic integration is examined in a multi-economy Schumpeterian growth model where economies differ in their research environment, and consequently in the productivity of $R \& D$. We show that economies with more or less the same productivity of $R \& D$ integrate. In equilibrium, there can be many common markets with different growth rates as well as stagnating economies with decreasing relative income. A small economy with low incentives to save can avoid stagnation, if its $R \& D$ is so productive that a common market with a positive growth rate can accept it as a member.
\end{abstract}

Journal of Economic Literature: F15, F21, O40

Keywords: endogenous growth, convergence, economic integration

Corresponding author:

Tapio Palokangas, Department of Economics, P.O.Box 17 (Arkadiankatu 7), FIN-00014 University of Helsinki, Finland. Phone +358 9191 28735, Fax +358 9191 28736, Email: Tapio.Palokangas@helsinki.fi

*Financial support from the Yrjö Jahnsson Foundation is gratefully acknowledged. The author is responsible for any possible remaining errors. 


\section{Introduction}

It is known that different institutions are reflected in the different level of productivity in the $R \& D$ sector. Many historically determined factors, e.g. bad working practises, a low standard of legal institutions and a high rate of criminality, decrease the productivity of $R \& D .{ }^{1}$ The EU is going to take new members which have weaker research environment than in the old members. It is instructing to examine the consequences of this change.

In this study, we show that the expansion of a common market to economies with lower productivity in $R \& D$ has two opposing effect on welfare. New members increase welfare through a wider variety of products, but on the other hand they decrease the average productivity in $R \& D$ in the common market, which lowers $R \& D$, the growth rate and welfare. When these two effects are balanced, an optimal common market obtains.

In this study, we also examine how country-specific differences in the productivity of $R \& D$ affect growth and economic integration. We give one possible explanation for the following stylized facts:

- There has been a wide dispersion in cross-country growth rates. ${ }^{2}$

- Many countries have had a common long-term growth rate. ${ }^{3}$

- Some small countries have been able to grow much faster than others. ${ }^{4}$

- Some countries started to grow much faster after establishing a common market with a greater economy. ${ }^{5}$

Common market studies have mainly concerned two aspects of integration: $(i)$ free trade, and $(i i)$ the equalization of the rates of return. Walz (1998) shows that the integration of a third, technologically lagging economy into a common market of two technologically advanced economies causes a reallocation of resources which stimulates overall growth. According to Baldwin and Forslid (2000), trade liberalization stimulates growth via increased

\footnotetext{
${ }^{1}$ See e.g. Barro (1998).

${ }^{2}$ See e.g. Barro and Sala-i-Martin (1995).

${ }^{3}$ See e.g. Howitt (2000), (2002).

${ }^{4}$ E.g. Ventura (1997) and the East Aasian Miracle.

${ }^{5}$ E.g. Ireland and Portugal after joining the EU.
} 
competition in the $R \& D$ and financial sectors. Peretto (2000) shows that integration slows down growth via higher fixed costs for a greater variety of goods, but speeds up growth via greater economies of scale. He argues that the latter effect tends to dominate and growth and welfare will rise. In contrast to these papers, we focus on a third aspect of economic integration, the reallocation of research activity among the member economies. From that viewpoint, common markets generate interesting development patterns. For instance, an economy, which did not undertake $R \& D$ before, may start doing so if it joins to a common market.

Howitt (2000) composes a model of creative destruction with international technology spillover. He specifies institutional aspects that impinge directly on the incentive to invest and innovate as shadow subsidies (or taxes) and obtains following results. Economies with $R \& D$ converge to parallel growth paths with different productivity levels, but the other economies stagnate. The world growth rate depends positively on $R \& D$ subsidy rate in all economies. In Howitt (2000), the main reason for the convergence of the national growth rates is that every economy with $R \& D$ gradually adopts the same frontier technology. In this paper, we show that the growth rates of all economies belonging to the same common market converge, although the economy-specific levels of productivity in $R \& D$ were exogenously given. Hence, no transfer of technology is needed to explain growth convergence.

The remainder of this paper is organized as follows. Section 2 presents the institutional assumptions and section 3 the basic model. Section 4 considers firms producing consumption and intermediate goods. Section 5 examines households, who save by investing in $R \& D$ firms in the same common market. Section 6 analyzes the effects of economic integration.

\section{The setting}

Each household supplies a fixed quantity of labour, which can be used either in production or in $R \& D$. Competitive firms assemble consumption goods from intermediate products, and local monopolies make intermediate goods from labour with constant returns to scale. $R \& D$ firms employ labour with constant returns to scale and try to make a better version of any of the 
intermediate-goods. Technological change is random, of quality ladders type. In the advent of success, a $R \& D$ firm drives the old local monopoly out of the market and takes over the production of the intermediate good. $R \& D$ firms finance their investment by issuing shares. The households save by investing in these shares. The level of productivity in the consumption-good sector is determined by $R \& D$ history.

There exists a great number $J$ of economies. The salient feature of the model is that the level of productivity $\lambda_{j}$ in $R \& D$ is given and differs throughout the economies $j=1, . ., J$. When $\lambda_{j}$ is high (low), we say that research environment is good (bad) in economy $j$. Any set of economies, $\Gamma \subset\{1, \ldots, J\}$, can form a common market. The size of this market is given by

$$
\theta(\Gamma) \doteq \int_{k \in \Gamma} d k \leq J
$$

The average productivity of $R \& D$ in common market $\Gamma$ is defined by

$$
\lambda(\Gamma) \doteq \frac{1}{\theta(\Gamma)} \int_{k \in \Gamma} \lambda_{k} d k .
$$

To focus on the effect of economic institutions, we make the following assumptions. There is no migration between economies. Intermediate goods are traded within the same common market, but not elsewhere. Firms can do $R \& D$ everywhere in the same common market. Households can invest in $R \& D$ firms operating in the same economy. Without these assumptions, the mathematical model would be excessively complicated.

In this setting, economic integration - i.e. the expansion of a common market - has two effects. New members increase welfare through a wider variety of products. On the other hand, if they have a lower productivity of $R \& D$ or a lower savings rate than the old members of the common market, technological change will be slower and the level of welfare lower for the old members. When these advantages and disadvantages of economic integration are balanced, the common market is of optimal size.

\section{The model}

Given the setting above, we now specify technology and preferences. 
(i) Producers. In each economy $j$, there is at a time one firm which produces intermediate good $j$ from local labour. A large number of firms produces the consumption good from all intermediate goods $k$ made in the same common market $\Gamma$ through Cobb-Douglas technology with constant returns to scale,

$$
C=\mu(\theta(\Gamma)) \prod_{k \in \Gamma}\left(B_{k} x_{k}\right)^{1 / \theta(\Gamma)}, \quad \mu^{\prime}>0
$$

where $C$ is consumption in common market $\Gamma, x_{k}$ the demand for intermediate input $k, B_{k}$ the productivity of input $k$ and $\theta(\Gamma)$ the size of $\Gamma$. The function $\mu(\theta)$ with $\mu^{\prime}>0$ characterizes the property that a wider variety of products (i.e. a bigger $\theta$ ) yields more services to the households and thereby increases welfare. ${ }^{6}$ This is the main motivation of economic integration.

(ii) $R \& D$ firms. The $R \& D$ firms located in economy $j \in \Gamma$ attempt to improve intermediate good $j$. They employ labour everywhere in the same common market $\Gamma$ and finance their expenditure wholly by issuing shares. Technological change in economy $j$ is characterized by a Poisson process $q_{j}$ as follows. The arrival rate of innovations in the $R \& D$ process is given by

$$
\Lambda_{j}=\int_{k \in \Gamma} \lambda_{k} z_{j k} d k
$$

where $z_{j k}$ is the demand for labour in economy $k$ by $R \& D$ firms located in economy $j$, and $\lambda_{k}$ the (exogenously given) productivity of $R \& D$ in economy $k$. During a short time interval $d t$, there is an innovation $d q_{j}=1$ with probability $\Lambda_{j} d t$, and no innovation $d q_{j}=0$ with probability $1-\Lambda_{j} d t$.

Because labour inputs $z_{j k}$ are prefect substitutes in the production function (4), $R \& D$ firms employ labour in the economy $k \in \Gamma$ with lowest unit cost $w_{k} / \lambda_{k}$. In equilibrium, $w_{j} / \lambda_{j}$ is then uniform for $j \in \Gamma$,

$$
w_{j}=\lambda_{j} w \text { for } j \in \Gamma
$$

where $w$ is the wage per effective labour in $R \& D$ in common market $\Gamma$.

(iii) Technological change. We denote the serial number of technology in economy $k$ by $t_{k}$. The level of productivity in the production of intermediate

\footnotetext{
${ }^{6}$ In other papers, the property that product variety increases welfare is commonly established through a $C E S$ production function. In this study, the replacement of the Cobb-Douglas function (3) by a $C E S$ function would excessively complicate the analysis.
} 
good $k, B_{k}\left(t_{k}\right)$, is determined by the currently most advanced technology $t_{k}$. The invention of a new technology raises $t_{k}$ by one and the level of productivity $B_{k}\left(t_{k}\right)$ by $\varepsilon>1$. This implies

$$
B_{k}\left(t_{k}\right)=B_{k}(0) \varepsilon^{t_{k}} .
$$

Because the average growth rates are in fixed proportion $(\log \varepsilon)$ to the arrival rates $\Lambda_{k},{ }^{7}$ we can use $\Lambda_{k}$ as proxies of the growth rates of economies. From the production function (3) it follows that in common market $\Gamma$ the level of productivity in the consumption-good sector is given by

$$
B \doteq \prod_{k \in \Gamma} B_{k}\left(t_{k}\right)^{1 / \theta(\Gamma)},
$$

and the average growth rate of consumption (= the arrival rate of jumps $\varepsilon>1$ in the level of productivity in the consumption-good sector) by

$$
\Lambda \doteq \frac{1}{\theta(\Gamma)} \int_{k \in \Gamma} \Lambda_{k} d k .
$$

Hence, we obtain the following result:

Proposition 1 The members of a common market $\Gamma$ have parallel consumption growth paths. They may have different levels of productivity, but their consumption grows at the same rate (8).

In contrast to Howitt (2000), where growth convergence results from international technology spillover, the unification of the growth rates is here caused by free movement of $R \& D$ firms in the common market.

(iv) Households. There is a fixed number $\kappa_{j}$ of households in economy $j$. These avert risk and maximize utility over an infinite horizon, given random technological change. We define the utility of household $\iota \in\left\{1, \ldots, \kappa_{j}\right\}$ in economy $j$ from an infinite stream of consumption beginning at time $T$ as:

$$
U_{j}\left(C_{j \iota}, T\right)=E \int_{T}^{\infty} \frac{C_{j \iota}^{1-\beta}-1}{1-\beta} e^{-\rho_{j}(\tau-T)} d \tau, \quad \rho_{j}>0, \quad \beta<1,
$$

where $\tau$ is time, $E$ the expectations operator, $C_{j \iota}$ consumption by household $\iota, \rho_{j}$ the constant rate of time preference and $\beta$ the constant degree of relative risk aversion.

\footnotetext{
${ }^{7}$ For this, see Aghion and Howitt (1998), p. 59.
} 
We denote household $\iota$ 's investment in $R \& D$ (= $\iota$ 's saving) in economy $j$ by $S_{j \iota}$. In economy $j$, aggregate investment by households, $\int_{\iota} S_{j \iota} d \iota$, is equal to the issue of shares by $R \& D$ firms, which in turn is equal to aggregate investment $\int_{k \in \Gamma} w_{k} z_{j k} d k$. Given (4) and (5), this condition takes the form

$$
\int_{\iota} S_{j \iota} d \iota=\int_{k \in \Gamma} w_{k} z_{j k} d k=w \int_{k \in \Gamma} \lambda_{k} z_{j k} d k=w \Lambda_{j}
$$

When a household has financed a successful $R \& D$ project, it acquires a certain share of the profit the successful firm earns. We assume that it receives a share of the firm's profit which is equal to its investment relative to total investment made in the same successful project. A successful project also implies that the old firm is driven out of the market. In such a case, all shares held by a household in the old firm lose their value.

Let $i_{j \iota}$ be household $\iota$ 's true share of the profits in economy $j$ when the uncertainty of the outcome of the projects is taken into account. Then,

$$
\int_{\iota=1}^{\kappa_{j}} i_{j_{\iota}} d j=1
$$

must be true. Following Wälde (1999a), we assume that the change in the true profit share, $d i_{j \iota}$, is a function of the increment $d q_{j}$ of a Poisson process $q_{j}$ and the investment share $I_{j \iota}$ of household $\iota$ out of total investment (10):

$$
d i_{j \iota}=\left(I_{j \iota}-i_{j \iota}\right) d q \text { for all } j \text { and } \iota, \text { where } I_{j \iota}=\frac{S_{j \iota}}{\int_{\iota \in \Gamma} S_{j \iota} d k}=\frac{S_{j \iota}}{w \Lambda_{j}} .
$$

When a household does not invest at all in the upcoming vintage (i.e. $I_{j \iota}=$ 0 ), its share-holdings are reduced to zero (i.e. $d i_{j \iota}=-i_{j \iota}$ ) in the case of $R \& D$ success $d q=1$. If it invests in the upcoming vintage, then the size of the share-holdings depends on relative investment $I_{j \iota}$.

\section{Production}

The representative consumption-good firm in common market $\Gamma$ maximizes its profit $\Pi \doteq P C-\int_{k \in \Gamma} p_{k} x_{k} d k$ by inputs $x_{k}, k \in \Gamma$, subject to technology (3), given the input prices $p_{k}, k \in \Gamma$, and the output price $P$. This yields

$$
p_{k}=P \frac{\partial C}{\partial x_{k}}=\frac{P C}{\theta(\Gamma) x_{k}} \text { for } k \in \Gamma .
$$


Each new generation of any intermediate good provides exactly $\varepsilon>1$ times as many services as the product of the generation before it. All potential producers of intermediate good $k$ take part in Bertrand competition and can produce one unit of their product from one labour unit. They maximize their profit $\pi_{k} \doteq p_{k} x_{k}-w_{k} x_{k}$ by their output $x_{k}$, given the wage in $k \in \Gamma$, $w_{k}$. One firm only has access to the technology for a state-of-art product, while another is able to manufacture the product that is one step behind on the quality ladder. To keep entrants away from the market, the incumbent firm sets its output price $p_{k}$ equal to $\varepsilon w_{k}$, which yields ${ }^{8}$

$$
p_{k}=\varepsilon w_{k}, \quad \pi_{k} \doteq p_{k} x_{k}-w_{k} x_{k}=(1-1 / \varepsilon) p_{k} x_{k} .
$$

Because there is no trade nor investment between the common markets, the price levels in these are totally independent. Hence, we can choose a separate numeraire for each common market $\Gamma$ and normalize total consumption expenditure $P C$ at $\theta(\Gamma)$. Given $P C=\theta(\Gamma),(13)$ and (14), we obtain

$$
p_{k} x_{k}=1, \quad \pi_{k}=1-1 / \varepsilon, \quad w_{k}=p_{k} / \varepsilon=1 /\left(\varepsilon x_{k}\right) .
$$

Labour devoted to $R \& D$ in economy $k$ is defined by

$$
z_{k} \doteq \int_{j \in \Gamma} z_{j k} d j
$$

We assume that in economy $k$ each of the $\kappa_{j}$ households supplies $1 / \kappa_{j}$ units of labour. Because there is no migration, $R \& D$ firms employ $z_{k}$ units and the intermediate-good firm $x_{k}$ units of labour, the equilibrium condition of the labour market in economy $k$ is then given by

$$
1=x_{k}+z_{k} \text { for all } k \text {. }
$$

Given (2), (8), (15), (16) and (17), we obtain

$$
\begin{aligned}
& \lambda_{k} / \lambda_{j}=w_{k} / w_{j}=x_{j} / x_{k} \text { for } j, k \in \Gamma, \quad \lambda_{j} x_{j}=\lambda_{k} x_{k} \text { for } j, k \in \Gamma, \\
& \Lambda \doteq \frac{1}{\theta} \int_{k \in \Gamma} \Lambda_{k} d k=\frac{1}{\theta} \int_{k \in \Gamma} \lambda_{k} z_{k} d k=\frac{1}{\theta} \int_{k \in \Gamma} \lambda_{k}\left(1-x_{k}\right) d k=\lambda-\lambda_{j} x_{j},
\end{aligned}
$$

which yield

$$
x_{j}=\frac{\lambda-\Lambda}{\lambda_{j}}, \quad w=\frac{w_{j}}{\lambda_{j}}=\frac{1}{\varepsilon \lambda_{j} x_{j}}=\frac{1}{\varepsilon} \frac{1}{\lambda-\Lambda} \text { for } j \in \Gamma, \quad \lambda>\Lambda .
$$

\footnotetext{
${ }^{8}$ Cf. Grossman and Helpman (1991), chapter 4.
} 


\section{Consumption and investment}

Household $\iota \in\left\{1, \ldots, \kappa_{j}\right\}$ in economy $j$ supplies $1 / \kappa_{j}$ units of labour, and receives the wage $w_{j}$ and the share $i_{j \iota}$ of the total profit of the intermediategood firm, $\pi_{j} \cdot{ }^{9}$ Given (5) and (15), its total income is then

$$
A_{j \iota}=\frac{w_{j}}{\kappa_{j}}+i_{j \iota} \pi_{j}=\frac{w_{j}}{\kappa_{j}}+\left(1-\frac{1}{\varepsilon}\right) i_{j \iota}=\lambda_{j} \frac{w}{\kappa_{j}}+\left(1-\frac{1}{\varepsilon}\right) i_{j \iota} .
$$

Because income $A_{j \iota}$ is equal to savings $S_{j \iota}$ plus consumption expenditure $P C_{j \iota}$, consumption $C_{j \iota}$ is determined by

$$
C_{j \iota}=\frac{A_{j \iota}-S_{j \iota}}{P}=\frac{1}{P}\left[\lambda_{j} \frac{w}{\kappa_{j}}+\left(1-\frac{1}{\varepsilon}\right) i_{j \iota}\right]-\frac{S_{j \iota}}{P} .
$$

Household $\iota$ maximizes its utility (9) subject to stochastic process (12) and the budget constraint $(21)$ by its saving $S_{j \iota}$, taking the wages $w_{j}$ and $w$, the consumption price $P$ and the arrival rate of innovations $\Lambda_{j}$ as given. We denote the value of receiving a share $i_{j \iota}$ of the profit of the producers possessing current technology $t_{j}$ by $\Omega\left(i_{j \iota}, t_{j}\right)$, and the value of receiving a share $I_{j}$ of the profit of the producers discovering the next technology $t_{j}+1$ by $\Omega\left(I_{j}, t_{j}+1\right)$. The Bellman equation for the household's program is then ${ }^{10}$

$$
\rho_{j} \Omega\left(i_{j \iota}, t_{j}\right)=\max _{S_{j \iota} \geq 0}\left\{C_{j \iota}^{1-\beta} /(1-\beta)+\Lambda_{j}\left[\Omega\left(I_{j \iota}, t_{j}+1\right)-\Omega\left(i_{j \iota}, t_{j}\right)\right]\right\},
$$

where $C_{j \iota}$ is given by (21). This leads to the first-order condition

$$
\Lambda_{j} \frac{\partial}{\partial S_{j \iota}}\left[\Omega\left(I_{j \iota}, t_{j}+1\right)-\Omega\left(i_{j \iota}, t_{j}\right)\right]=-C_{j \iota}^{-\beta} \frac{\partial C_{j \iota}}{\partial S_{j \iota}}=C_{j \iota}^{-\beta} / P .
$$

We focus entirely on the households' stationary equilibrium in which the allocation of resources is invariable across technologies, and ignore dynamics during the transitional period before the equilibrium is reached. We try the solution that consumption expenditure $P C_{j \iota}$ is a share $0 \leq c_{j \iota} \leq 1$ of income $A_{j \iota}$, and that the value function is

$$
\Omega=\left(c_{j \iota} A_{j \iota}\right)^{1-\beta} /\left[(1-\beta) r_{j \iota}\right],
$$

\footnotetext{
${ }^{9}$ Because the consumption-good firms are subject to constant returns to scale, in equilibrium they do not yield profits.

${ }^{10}$ Cf. Dixit and Pindyck (1994), and Wälde (1999a), (1999b).
} 
where the expenditure-income ratio $c_{j \iota}$ and the household's subjective interest rate $r_{j \iota}$ are independent of income $A_{j \iota}$. Inserting these solutions into (22) and (23), we obtain that in common market $\Gamma$ the subjective interest rates $r_{j \iota}$ and the expenditure-income ratios $c_{j \iota}$ are uniform (Appendix $A$ ):

$$
\begin{aligned}
& r_{j \iota}=r_{j} \doteq \rho_{j}+\left[1-\varepsilon^{1-\beta} \theta(\Gamma)^{\beta-1}\right] \Lambda_{j}>0 \text { for all } j \in \Gamma, \\
& 1-\frac{S_{j \iota}}{A_{j \iota}}=c_{j \iota}=c_{j} \doteq \min \left\{1, \frac{\rho_{j}+\left[1-\varepsilon^{1-\beta} \theta(\Gamma)^{\beta-1}\right] \Lambda_{j}}{(\varepsilon-1)(\lambda-\Lambda)(\varepsilon / \theta)^{1-\beta}}\right\} \text { for all } j \in \Gamma .
\end{aligned}
$$

Now we can show the following:

Proposition 2 A non-integrated economy $j$ does not grow at all, if its households are impatient enough for $\rho_{j} \geq(\varepsilon-1) \lambda_{j} \varepsilon^{1-\beta}$ to hold.

Proof: Given (19), (25) and (26), economy $j \in \Gamma$ saves $\left(c_{j}<1\right)$ only if

$$
(\varepsilon-1)(\lambda-\Lambda) \varepsilon^{1-\beta} \theta(\Gamma)^{\beta-1}>\rho_{j}+\left[1-\varepsilon^{1-\beta} \theta(\Gamma)^{\beta-1}\right] \Lambda_{j} .
$$

If condition (27) does not hold, then economy $j \in \Gamma$ consumes all its income, $c_{j}=1$. If this economy is left alone as a separate common market, $\Gamma=\{j\}$ and $\theta=1$, then, given (2), (4), (10) and (26), it does not save nor invest in $R \& D, S_{j \iota}=z_{j}=0$, consequently it does not grow at all, $\Lambda=\Lambda_{j}=0$, and $\lambda=\lambda_{j}$. Inequality (27) takes then the form $(\varepsilon-1) \lambda_{j} \varepsilon^{1-\beta}>\rho_{j}$. Hence, $\Lambda_{j}=0$ for $\rho_{j} \geq(\varepsilon-1) \lambda_{j} \varepsilon^{1-\beta}$.

\section{Economic integration}

In Appendix $B$, we prove

$$
\Lambda\left(\Gamma,\left\{\rho_{k \in \Gamma}\right\},\left\{\lambda_{k \in \Gamma}\right\}\right), \quad \lim _{\theta \rightarrow \infty} \frac{\partial \Lambda}{\partial \lambda_{j}}>0 \text { for } j \in \Gamma .
$$

where $\left\{\rho_{k \in \Gamma}\right\}$ and $\left\{\lambda_{k \in \Gamma}\right\}$ denote $\rho_{k}$ and $\lambda_{k}$ for all $k \in \Gamma$. Total consumption in common market $\Gamma$ is obtained by summing throughout all economies and households in $\Gamma, C \doteq \int_{j \in \Gamma}\left(\int_{\iota_{1}}^{\kappa_{j}} C_{j_{\iota}} d \iota\right) d j$. In the stationary state, given (3), (7), (19) and (28), we can define

$$
\begin{aligned}
\frac{C}{B} & =\mu(\theta(\Gamma)) \prod_{k \in \Gamma} x_{k}^{1 / \theta(\Gamma)}=\mu(\theta(\Gamma))\left[\lambda(\Gamma)-\Lambda\left(\Gamma,\left\{\rho_{k \in \Gamma}\right\},\left\{\lambda_{k \in \Gamma}\right\}\right)\right] \prod_{k \in \Gamma} \lambda_{k}^{-1 / \theta(\Gamma)} \\
& \doteq \chi\left(\Gamma,\left\{\rho_{k \in \Gamma}\right\},\left\{\lambda_{k \in \Gamma}\right\}\right), \quad \lim _{\theta \rightarrow \infty} \frac{\partial \chi}{\partial \lambda_{j}}>0 \text { for } j \in \Gamma
\end{aligned}
$$


Given (2), (9), (28) and (29), we obtain the welfare of the representative household in common market $\Gamma$ of size $\theta(\Gamma)$ as follows:

$$
U=E \int_{T}^{\infty} \frac{1}{1-\beta} C^{1-\beta} e^{-\rho(\tau-T)} d \tau=E \int_{T}^{\infty} \frac{1}{1-\beta} \chi^{1-\beta} B^{1-\beta} e^{-\rho(\tau-T)} d \tau .
$$

The arrival rate of Poisson jumps in the level of consumption, $B$, is given by (8). The social planner chooses the members of the common market (i.e. the set $\Gamma$ ) among those who are willing to join in this to maximize welfare (30) subject to the Poisson process. Denoting the value of the state of technology $t$ for the planner by $\Psi\left(t,\left\{\rho_{k \in \Gamma}\right\},\left\{\lambda_{k \in \Gamma}\right\}\right)$, the Bellman equation for the planner's optimization reads: ${ }^{11}$

$$
\rho \Psi\left(t,\left\{\rho_{k \in \Gamma}\right\},\left\{\lambda_{k \in \Gamma}\right\}\right)=\max _{\Gamma} \Phi\left(t, \Gamma,\left\{\rho_{k \in \Gamma}\right\},\left\{\lambda_{k \in \Gamma}\right\}\right)
$$

where, given (28) and (29),

$$
\begin{aligned}
\Phi\left(t, \Gamma,\left\{\rho_{k \in \Gamma}\right\},\left\{\lambda_{k \in \Gamma}\right\}\right) \doteq & B(t)^{1-\beta} \chi\left(\Gamma,\left\{\rho_{k \in \Gamma}\right\},\left\{\lambda_{k \in \Gamma}\right\}\right)^{1-\beta} /(1-\beta) \\
& +\Lambda\left(\Gamma,\left\{\rho_{k \in \Gamma}\right\},\left\{\lambda_{k \in \Gamma}\right\}\right)[\Psi(t+1, \rho)-\Psi(t, \rho)] \\
\lim _{\theta \rightarrow \infty} \frac{\partial \Phi}{\partial \lambda_{j}}>0 \text { for } j \in \Gamma &
\end{aligned}
$$

To simplify the analysis, we assume that a common market expands by taking new members economy by economy and that an economy can freely leave the common market whenever it wants to do so. We can then prove:

Proposition 3 In equilibrium, there can be a number of common markets with different positive growth rates as well as a number of stagnating economies which do not grow at all.

ProOF: Let 1 be the economy which is most productive in $R \& D$ in the whole world, $\lambda_{1}=\max _{k} \lambda_{k}$, and $\Gamma_{1}$ the frontier common market containing economy 1. If economy 1 forms this common market alone, $\Gamma_{1}=\{1\}$, then it prefers economy 2 as the second member, and these two together economy 3 as the third member, etc. Given (31), common market $\Gamma_{1}$ expands, until

\footnotetext{
${ }^{11}$ We solve for the value function $\Psi$ in Appendix $C$.
} 
any new member $j$ would decrease welfare in $\Gamma_{1}$ or any economy $j$ would decrease its welfare by joining in $\Gamma_{1}$ :

$$
\begin{aligned}
& \Phi\left(t, \Gamma_{1},\left\{\rho_{k \in \Gamma_{1}}\right\},\left\{\lambda_{k \in \Gamma_{1}}\right\}\right)>\Phi\left(t, \Gamma_{1}+\{j\},\left\{\rho_{k \in \Gamma_{1}}\right\}, \rho_{j},\left\{\lambda_{k \in \Gamma_{1}}\right\}, \lambda_{j}\right) \text { or } \\
& \Phi\left(t,\{j\}, \rho_{j}, \lambda_{j}\right)>\Phi\left(t, \Gamma_{1}+\{j\},\left\{\rho_{k \in \Gamma_{1}}\right\}, \rho_{j},\left\{\lambda_{k \in \Gamma_{1}}\right\}, \lambda_{j}\right) \\
& \text { for all } j>\theta_{1}=\theta\left(\Gamma_{1}\right)=\int_{\Gamma_{1}} d k .
\end{aligned}
$$

Let $\theta_{1}+1$ which is the most productive in $R \& D$ among those left outside $\Gamma_{1}$ and $\Gamma_{2}$ the common market containing economy $\theta_{1}+1$. By the same reasoning as above, we obtain the following equilibrium condition for $\Gamma_{2}$ :

$$
\begin{aligned}
& \Phi\left(t, \Gamma_{2},\left\{\rho_{k \in \Gamma_{2}}\right\},\left\{\lambda_{k \in \Gamma_{2}}\right\}\right)>\Phi\left(t, \Gamma_{2}+\{j\},\left\{\rho_{k \in \Gamma_{2}}\right\}, \rho_{j},\left\{\lambda_{k \in \Gamma_{2}}\right\}, \lambda_{j}\right) \text { or } \\
& \Phi\left(t,\{j\}, \rho_{j}, \lambda_{j}\right)>\Phi\left(t, \Gamma_{2}+\{j\},\left\{\rho_{k \in \Gamma_{2}}\right\}, \rho_{j},\left\{\lambda_{k \in \Gamma_{2}}\right\}, \lambda_{j}\right) \\
& \text { for all } j>\theta_{2}=\theta\left(\Gamma_{2}\right)=\int_{\Gamma_{2}} d k .
\end{aligned}
$$

Hence, by induction, we obtain a (finite) sequence $\left\{\Gamma_{i}\right\}$ of common markets. Outside sets $\left\{\Gamma_{i}\right\}$, there are only economies which do not grow at all.

The following corollary obtains:

Proposition 4 (Windows of opportunity) Consider economy $j \in \Theta$ which has too weak saving incentives (i.e. with a high $\rho_{j}$ ) to grow if left alone. This economy can grow if the productivity of its $R \& D, \lambda_{j}$, is so high that it can join a large common market with a positive growth rate.

Proof: Proposition 2 suggests that if $\rho_{j} \geq(\varepsilon-1) \lambda_{j} \varepsilon^{1-\beta}$, then economy $j$ does not grow at all. Assume that the productivity of $R \& D$ in economy $j$, $\lambda_{j}$, is higher than $\min _{k \in \Gamma} \lambda_{k}$ for any common market $\Gamma$ of size $\theta(\Gamma)$. From $\lim _{\theta \rightarrow \infty}\left(\partial \Phi / \partial \lambda_{j}\right)>0$ in (32) then follows that common market $\Gamma$ takes economy $j$ as a member. Combining these two equalities, we obtain that when common market $\Gamma$ is large enough and the productivity of $R \& D$ in economy $j, \lambda_{j}$, is within the range $\min _{k \in \Gamma} \lambda_{k}<\lambda_{j} \leq \rho_{j} /\left[(\varepsilon-1) \varepsilon^{1-\beta}\right]$, then economy $j$ does not grow at all if left alone, but starts growing if it joins common market $\Gamma$.

Propositions 3 and 4 are interpreted in the final section. 


\section{Conclusions}

This paper examines a multi-economy world where growth is generated by creative destruction as follows. Consumption is produced from intermediate goods. A $R \& D$ firm creating the latest technology of an intermediate good through a successful $R \& D$ project crowds the other firms with older technologies out of the market so that they lose their value. The firms finance their $R \& D$ by selling shares, and households save only by buying these shares. Any set of economies can form a common market in which intermediate goods are freely traded and $R \& D$ firms can freely operate. We examine the effects of the establishment and expansion of a common market on growth and social welfare. The main findings can be summarized as follows.

Common markets that do more $R \& D$, produce more innovations and grow faster. The expansion of a common market has two effects. New members increase welfare through a wider variety of products. On the other hand, if the new members have a lower productivity of $R \& D$ or a lower savings rate than the old members of the common market, technological change will be slower and the level of welfare lower for the old members. When these advantages and disadvantages of economic integration are balanced, the common market is of optimal size.

Economies integrate only if their productivity of $R \& D$ is more or less the same. After integration they grow at the same rate, but at different levels of productivity. The integration of two economies increases the growth rate of the one whose $R \& D$ is less productive and decreases that of the other whose $R \& D$ is more productive. If the productivity of $R \& D$ differs too much for them, then the latter declines the integration. For it, the welfare loss of a lower growth rate outweighs the welfare benefit of a wider variety of products.

Because economies with roughly the same productivity of $R \& D$ integrate, there can be a number of common markets with different growth rates. Some economies stagnate, because their incentives to save are too weak (e.g. households are too impatient) for $R \& D$ and growth. Such an economy can, however, escape from stagnation if it is productive enough in $R \& D$ to join in a large common market with persistent growth. Because its $R \& D$ projects are after integration financed by the savings of the other member economies, it can then grow even without domestic saving. 


\section{Appendix}

\section{A. The Behaviour of a Household}

We denote variables depending on on technology $t_{j}$ by superscript $t_{j}$. Since, given (20), household $\iota$ 's income $A_{j \iota}^{t_{j}}$ depends on $i_{j \iota}^{t_{j}}$, we note $A_{j_{\iota}}^{t_{j}}\left(i_{j_{\iota}}^{t_{j}}\right)$. On the assumption that $c_{j}$ is invariable across technologies, we obtain

$$
P^{t_{j}} C_{j \iota}^{t_{j}}=c_{j} A_{j_{\iota}}^{t_{j}}\left(i_{j_{\iota}}^{t_{j}}\right), \quad S_{j \iota}^{t_{j}}=\left(1-c_{j}\right) A_{j_{\iota}}^{t_{j}}\left(i_{j_{\iota}}^{t_{j}}\right)=\left(1 / c_{j}-1\right) P^{t_{j}} C_{j \iota}^{t_{j}} .
$$

Household $\iota$ 's share in the next producer $t_{j}+1$ is determined by its investment under technology $t_{j}, i_{j \iota}^{t_{j}+1}=I_{j \iota}^{t_{j}}$. Given (24), the value functions are

$$
\begin{aligned}
& \Omega\left(i_{j \iota}^{t_{j}}, t_{j}\right)=\frac{\left(C_{j \iota}^{t_{j}}\right)^{1-\beta}}{(1-\beta) r_{j}}=\frac{\left[c_{j} A_{j_{\iota}}^{t_{j}}\left(i_{j_{\iota}}^{t_{j}}\right) / P^{t_{j}}\right]^{1-\beta}}{(1-\beta) r_{j}}, \\
& \Omega\left(I_{j \iota}^{t_{j}}, t_{j}+1\right)=\frac{\left(C_{j \iota}^{t_{j}+1}\right)^{1-\beta}}{(1-\beta) r_{j}}=\frac{\left[c_{j} A_{j \iota}^{t_{j}+1}\left(I_{j \iota}^{t_{j}}\right) / P^{t_{j}+1}\right]^{1-\beta}}{(1-\beta) r_{j}} .
\end{aligned}
$$

Given this and (20), we obtain

$$
\partial \Omega\left(i_{j \iota}^{t_{j}}, t_{j}\right) / \partial S_{j \iota}^{t_{j}}=0 .
$$

From (4), (2), (12), (20) and (34) it follows that

$$
\begin{gathered}
\frac{\partial I_{j \iota}^{t_{j}}}{\partial S_{j}^{t_{j}}}=\frac{1}{w^{t_{j}} \Lambda_{j}^{t_{j}}}, \quad \frac{\partial\left[A_{j \iota}^{t_{j}+1}\left(I_{j \iota}^{t_{j}}\right)\right]}{\partial I_{j \iota}^{t_{j}}}=\frac{\partial\left[A_{j \iota}^{t_{j}+1}\left(i_{j \iota}^{t_{j}+1}\right)\right]}{\partial i_{j \iota}^{t_{j}+1}}=1-\frac{1}{\varepsilon}, \\
\frac{\partial \Omega\left(I_{j \iota}^{t_{j}}, t_{j}+1\right)}{\partial S_{j}^{t_{j}}}=(1-\beta) \frac{\Omega\left(I_{j \iota}^{t_{j}}, t_{j}+1\right)}{A_{j \iota}^{t_{j}+1}} \frac{\partial A_{j \iota}^{t_{j}+1}}{\partial I_{j}^{t_{j}}} \frac{\partial I_{j}^{t_{j}}}{\partial S_{j}^{t_{j}}} \\
=\left(1-\frac{1}{\varepsilon}\right)(1-\beta) \frac{\Omega\left(I_{j \iota}^{t_{j}}, t_{j}+1\right)}{A_{j \iota}^{t_{j}+1} w^{t_{j}} \Lambda_{j}^{t_{j}}} .
\end{gathered}
$$

We focus on a stationary equilibrium in which the allocation of labour in (17) is invariable across technologies, $z_{j}^{t_{j}}=z_{j}$ and $x_{j}^{t_{j}}=x_{j}$. Given this, (4), (15), (20) and (33), wages, income, expenditure and the arrival of innovations are also invariable across technologies, $w^{t_{j}}=w, A_{j \iota}^{t_{j}}=A_{j \iota}$, $P^{t_{j}} C_{j \iota}^{t_{j}}=P^{t_{j}+1} C_{j \iota}^{t_{j}+1}$ and $\Lambda_{j}^{t_{j}}=\Lambda_{j}$. Because in a stationary state consumption $C_{j \iota}^{t_{j}}$ and the level of productivity in the consumption-good sector, $B^{t_{j}}$, 
grow at the same rate, given (7) and (34), we obtain

$$
\begin{aligned}
& P^{t_{j}} / P^{t_{j}+1}=C_{j \iota}^{t_{j}+1} / C_{j \iota}^{t_{j}}=B^{t_{j}+1} / B^{t_{j}}=[1 / \theta(\Gamma)] B_{j}\left(t_{j}+1\right) / B_{j}\left(t_{j}\right)=\varepsilon / \theta(\Gamma), \\
& \Omega\left(I_{j \iota}^{t_{j}}, t_{j}+1\right) / \Omega\left(i_{j \iota}^{t_{j}}, t\right)=\left(C_{j \iota}^{t_{j}+1} / C_{j \iota}^{t_{j}}\right)^{1-\beta}=\varepsilon^{1-\beta} \theta(\Gamma)^{\beta-1} .
\end{aligned}
$$

Inserting these results, (33) and (34) into equation (22), we obtain

$$
\begin{aligned}
0 & =\left(\rho_{j}+\Lambda_{j}\right) \Omega\left(i_{j \iota}^{t_{j}}, t\right)-\left(C_{j \iota}^{t_{j}}\right)^{1-\beta} /(1-\beta)-\Lambda_{j} \Omega\left(I_{j \iota}^{t_{j}}, t_{j}+1\right) \\
& =\left\{\rho_{j}-r_{j}+\left[1-\varepsilon^{1-\beta} \theta(\Gamma)^{\beta-1}\right] \Lambda_{j}\right\} \Omega\left(i_{j \iota}^{t_{j}}, t\right) .
\end{aligned}
$$

This leads to (25).

Inserting (19), (25) and (33)-(37) into (23) and noting (15) produce

$$
\begin{aligned}
0 & =\Lambda_{j}\left[\frac{\partial \Omega\left(I_{j \iota}^{t_{j}}, t_{j}+1\right)}{\partial S_{j}^{t_{j}}}-\frac{\partial \Omega\left(i_{j}^{t_{j}}, t\right)}{\partial S_{j}^{t_{j}}}\right]-\frac{\left(C_{j \iota}^{t_{j}}\right)^{-\beta}}{P^{t_{j}}} \\
& =(1-1 / \varepsilon)(1-\beta) \Omega\left(I_{j \iota}^{t_{j}}, t_{j}+1\right) /\left(A_{j \iota} w\right)-\left(C_{j \iota}^{t_{j}}\right)^{-\beta} / P^{t_{j}} \\
& =(\varepsilon-1)(\lambda-\Lambda)(1-\beta) \Omega\left(I_{j \iota}^{t_{j}}, t_{j}+1\right) / A_{j \iota}-\left(C_{j \iota}^{t_{j}}\right)^{-\beta} / P^{t_{j}} \\
& =\left[(\varepsilon-1)(\lambda-\Lambda)(1-\beta) \frac{P^{t_{j}} \Omega\left(I_{j \iota}^{t_{j}}, t_{j}+1\right)}{A_{j \iota}\left(C_{j \iota}^{t_{j}}\right)-\beta}-1\right] \frac{\left(C_{j \iota}^{t_{j}}\right)^{-\beta}}{P^{t_{j}}} \\
& =\left[(\varepsilon-1)(\lambda-\Lambda)(1-\beta) \varepsilon^{1-\beta} \theta(\Gamma)^{\beta-1} \frac{P^{t_{j}} \Omega\left(i_{j \iota}^{t_{j}}, t\right)}{A_{j \iota}\left(C_{j \iota}^{t_{j}}\right)^{-\beta}}-1\right] \frac{\left(C_{j \iota}^{t_{j}}\right)^{-\beta}}{P^{t_{j}}} \\
& =\left[(\varepsilon-1)(\lambda-\Lambda) \varepsilon^{1-\beta} \theta(\Gamma)^{\beta-1} \frac{P^{t_{j}} C_{j \iota}^{t_{j}}}{A_{j_{\iota}} r_{j}}-1\right] \frac{\left(C_{j \iota}^{t_{j}}\right)^{-\beta}}{P^{t_{j}}} \\
& =\left[(\varepsilon-1)(\lambda-\Lambda) \varepsilon^{1-\beta} \theta(\Gamma)^{\beta-1} \frac{c_{j}}{r_{j}}-1\right] \frac{\left(C_{j \iota}^{t_{j}}\right)^{-\beta}}{P^{t_{j}}} \\
& =\left\{\frac{(\varepsilon-1)(\lambda-\Lambda) \varepsilon^{1-\beta} \theta(\Gamma)^{\beta-1} c_{j}}{\rho_{j}+\left[1-\varepsilon^{1-\beta} \theta(\Gamma)^{\beta-1}\right] \Lambda_{j}}-1\right\} \frac{\left(C_{j_{\iota}}^{t_{j}}\right)^{-\beta}}{P^{t_{j}}} .
\end{aligned}
$$

This, (25) and $c_{j}<1$ yield (26), the expenditure-income ratio.

\section{B. The function (28)}

From this, (1), (2), (8), (10), (11), (19), (20), (26) it follows that

$$
\begin{aligned}
\Lambda_{j} & =\frac{1}{w} \int_{\iota} S_{j \iota} d \iota=\left(1-c_{j}\right) A_{j} / w=\left(1-c_{j}\right)\left[\lambda_{j}+(1-1 / \varepsilon) / w\right] \\
& =\left(1-c_{j}\right)\left\{\lambda_{j}+(\varepsilon-1)[\lambda(\Gamma)-\Lambda]\right\} \text { for } j \in \Gamma,
\end{aligned}
$$




$$
\begin{aligned}
& \Lambda \doteq \frac{1}{\theta} \int_{k \in \Gamma} \Lambda_{k} d k=\frac{1}{\theta} \int_{k \in \Gamma}\left(1-c_{k}\right)\left[\lambda_{k}+(\varepsilon-1)(\lambda-\Lambda)\right] d k \\
&= \frac{1}{\theta} \int_{k \in \Gamma}\left(1-c_{k}\right) \lambda_{k} d k+(\varepsilon-1)(\lambda-\Lambda) \frac{1}{\theta} \int_{k \in \Gamma}\left(1-c_{k}\right) d k \\
&= \frac{1}{\theta} \int_{k \in \Gamma} \lambda_{k} d k-\frac{1}{\theta} \int_{k \in \Gamma} c_{k} \lambda_{k} d k \\
& \quad+(\varepsilon-1)(\lambda-\Lambda)\left(\frac{1}{\theta} \int_{k \in \Gamma} d k-\frac{1}{\theta} \int_{k \in \Gamma} c_{k} d k\right) \\
&= \lambda(\Gamma)-\frac{1}{\theta(\Gamma)} \int_{k \in \Gamma} c_{k} \lambda_{k} d k+(\varepsilon-1)[\lambda(\Gamma)-\Lambda]\left(1-\frac{1}{\theta} \int_{k \in \Gamma} c_{k} d k\right), \\
&(\varepsilon-1)(\lambda-\Lambda) \varepsilon^{1-\beta} \theta^{\beta-1} c_{j}=\rho_{j}+\left(1-\varepsilon^{1-\beta} \theta^{\beta-1}\right) \Lambda_{j} \text { for } j \in \Gamma .
\end{aligned}
$$

In the system (38)-(40), there are $2 \theta+1$ equations, $2 \theta+1$ endogenous variables $\left(\Lambda_{j}\right.$ and $c_{j}$ for $j \in \Gamma$, and $\left.\lambda\right)$ and exogenous variables $\lambda_{k}$ and $\rho_{k}$ for $j \in \Gamma$. This system defines the function $\chi$ in (28).

The expenditure-income ratio $c_{k}$, the average productivity in $R \& D, \lambda$, and the arrival rate of innovations in the $R \& D$ process, $\Lambda$, are constrained functions. Noting this and (2), differentiating (39) totally and letting $\theta$ to be large enough, we obtain $d \Lambda / d \lambda_{j}=d \lambda / d \lambda_{j}=1 / \theta>0$.

\section{The value function $\Psi$}

We try the solution

$$
\Psi\left(t, \rho_{k \in \Gamma}, \lambda_{k \in \Gamma}\right)=\psi \chi\left(\Gamma, \rho_{k \in \Gamma}, \lambda_{k \in \Gamma}\right)^{1-\beta} B(t)^{1-\beta} /(1-\beta),
$$

where the variable $\psi$ is independent of the endogenous variables of the system. This and (6) yields

$$
\Psi\left(t+1, \rho_{k \in \Gamma}, \lambda_{k \in \Gamma}\right) / \Psi\left(t, \rho_{k \in \Gamma}, \lambda_{k \in \Gamma}\right)=[B(t+1) / B(t)]^{1-\beta}=\varepsilon^{1-\beta}>0 .
$$

Substituting (32), (41) and (42) into the Bellman equation (31), we obtain

$$
\begin{aligned}
0= & \phi^{1-\beta} B(t)^{1-\beta} /(1-\beta)+\left[\Psi\left(t+1, \rho_{k \in \Gamma}, \lambda_{k \in \Gamma}\right)-\Psi\left(t, \rho_{k \in \Gamma}, \lambda_{k \in \Gamma}\right)\right] \Lambda \\
& \quad-\rho \Psi\left(t, \rho_{k \in \Gamma}, \lambda_{k \in \Gamma}\right) \\
= & \Psi\left(t, \rho_{k \in \Gamma}, \lambda_{k \in \Gamma}\right)\left[1 / \psi+\left(\varepsilon^{1-\beta}-1\right) \Lambda-\rho\right], \\
\psi= & 1 /\left[\rho+\left(1-\varepsilon^{1-\beta}\right) \Lambda\right] .
\end{aligned}
$$


Inserting $\psi$ back into (41) yields the value function

$$
\begin{aligned}
& \Psi\left(t, \rho_{k \in \Gamma}\right) \\
& =\chi\left(\Gamma, \rho_{k \in \Gamma}, \lambda_{k \in \Gamma}\right)^{1-\beta} B(t)^{1-\beta} /\left\{(1-\beta)\left\{\rho+\left[1-\varepsilon^{1-\beta} \theta(\Gamma)^{\beta-1}\right] \Lambda(\Gamma)\right\}\right\} .
\end{aligned}
$$

\section{References:}

Aghion, P. and Howitt, P., 1998. Endogenous Growth Theory. MIT Press, Cambridge (Mass.).

Baldwin, R.E. and Forslid, R., 2000. Trade liberalization and endogenous growth: a q-theory approach. Journal of International Economics 50, 497517.

Barro, R.J., 1998. Determinants of Economic Growth. MIT Press, Cambridge (Mass.).

Barro, R.J. and Sala-i-Martin, X., 1994. Economic Growth. McGraw-Hill, New York.

Dixit, A. and Pindyck, K., 1994. Investment under Uncertainty. Princeton University Press, Princeton.

Grossman, G. and Helpman, E., 1991. Innovation and Growth. Cambridge (Mass.): The MIT Press.

Howitt, P., 2000. Endogenous growth and cross country differences. American Economic Review 90, 829-846.

Howitt, P., 2002. R\&D, implementation and stagnation: a schumpeterian theory of convergence clubs. NBER Working Paper No. 9104.

Peretto, P.F., 2000. Endogenous market structure and the growth and welfare effects of economic integration, Working Paper, Duke University.

Ventura, J., 1997. Growth and interdependence. The Quarterly Journal of Economics 112, 57-84.

Walz, U., 1998. Does an enlargement of a common market stimulate growth and convergence. Journal of International Economics 45, 297-321.

Wälde, K., 1999a. A model of creative destruction with undiversifiable risk and optimizing households. The Economic Journal 109, C156-C171.

Wälde, K., 1999b. Optimal saving under poisson uncertainty. Journal of Economic Theory 87, 194-217. 